\title{
Trigona corvina: An Ecological Study Based on Unusual Nest Structure and Pollen Analysis
}

\author{
David W. Roubik and J. Enrique Moreno Patiño \\ Smithsonian Tropical Research Institute, 0843-03092 Balboa, Panama \\ Correspondence should be addressed to David W. Roubik, roubikd@si.edu \\ Received 1 March 2009; Accepted 9 July 2009 \\ Recommended by Howard Ginsberg
}

We found that the nest of Trigona corvina (Apidae; Meliponini) consists mainly of pollen exines from bee excrement, forming a scutellum shield encasing the colony. A 20-year-old nest (1980-2000) from a lowland Panama forested habitat was sawed in half longitudinally, and a $95 \mathrm{~cm}$ transect was systematically sampled each $5 \mathrm{~cm}$. Samples subjected to detailed pollen analysis held 72 botanical species belonging to 65 genera in 41 families. Over $90 \%$ of scutellum pollen volume was Cecropiaceae and Arecaceae, among $>10^{13}$ grains. Potentially the oldest samples, in the middle of the nest, indicate that Mimosoideae, Euphorbiaceae, and Bombacaceae (now Malvaceae) were lost when Africanized honey bee competitors colonized Panama in 1984. Cecropia deposited in the nest increased markedly after landscape-level vegetation disturbance. Pollen from Cavanillesia demonstrated that the foraging range encompassed $3 \mathrm{~km}^{2}$ and perhaps 500 plant species. Trigona corvina primarily foraged on plants with large inflorescences, consistent with foraging theory considering their aggressive behavior.

Copyright (C) 2009 D. W. Roubik and J. E. Moreno Patiño. This is an open access article distributed under the Creative Commons Attribution License, which permits unrestricted use, distribution, and reproduction in any medium, provided the original work is properly cited.

\section{Introduction}

Relatively few stingless bees, tribe Meliponini, build their entire domicile, because most use pre-existing cavities [1]. Even fewer provide a record of plant resources they have consumed [2]. Trigona corvina does both. This Neotropical genus of over 40 species [3] consists primarily of aggressive bees living in nests exposed on small branches or large surfaces-not within tree or ground cavities [3-5]. A $140 \mathrm{~kg}$ nest of Trigona corvina broke from its supporting treetop branch after 20 years, and DWR happened to observe both inception of the nest and its fall. It was rolled on logs into the back of a pickup truck and taken to a cold storage room at the Smithsonian Tropical Research Institute, Tupper Building, in Balboa, Panama. The nest was split longitudinally with a chain saw. Half was shipped to the Hunterian Museum in Glasgow, Scotland, now on permanent display as an exemplar of animal architecture. The remainder is described and analyzed here. We applied melittopalynology - the analysis of bee-collected pollen [6].

\section{Methods}

Foundation of the colony was noted at the site by DWR in 1980, during a visit to R. L. Dressler. In Curundu Flats, Ancon, a large patch of several thousand worker T. corvina was observed at $15 \mathrm{~m}$ from the ground on an ornamental tree, Lagerstroemia (Lythraceae) at the Dressler residence. The nest was completed during approximately one month as an ovoid dark mass $[5,7]$ around a $10 \mathrm{~cm}$ diameter apical stem of the tree. The size of the nest steadily increased during the next 20 years, and it was observed frequently. The mature nest had an outer covering with irregular holes of approximately $1-3 \mathrm{~cm}$ diameter, separated by $1-3 \mathrm{~cm}$ from each other, and long, slender tubercles of approximately three to ten $\mathrm{cm}$ in length surrounding the lower half of the ovoid nest entrance tube, which projected a few centimeters from the nest surface (Figure 1). On the day the nest fell it was retrieved and placed in cold storage, with defensive bees still inside, as stated in Section 1.

Later the nest was sawed in half from top to bottom. A transect was made along the maximum length and a cubic $\mathrm{cm}$ 


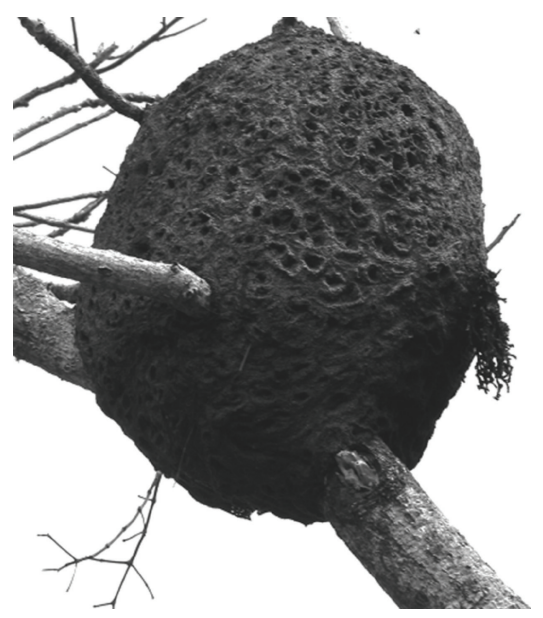

(a)

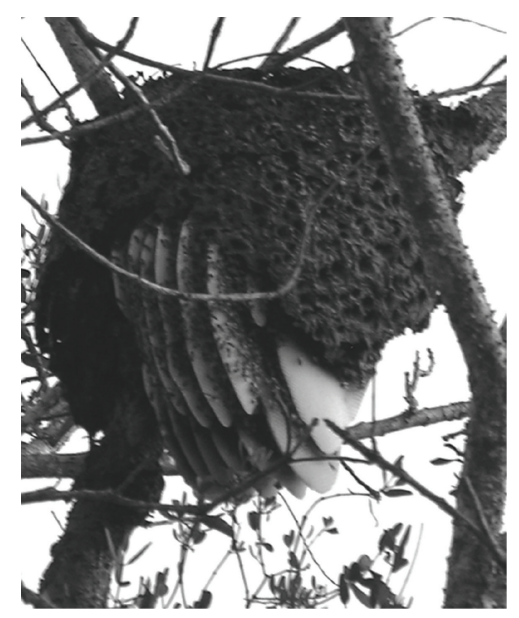

(b)

Figure 1: (a) Active nest of Trigona corvina, Cerro Campana, Panama. (b) Active nest of Africanized Apis mellifera established in the scutellum of Trigona corvina near Summit Gardens, Panama city, Panama.

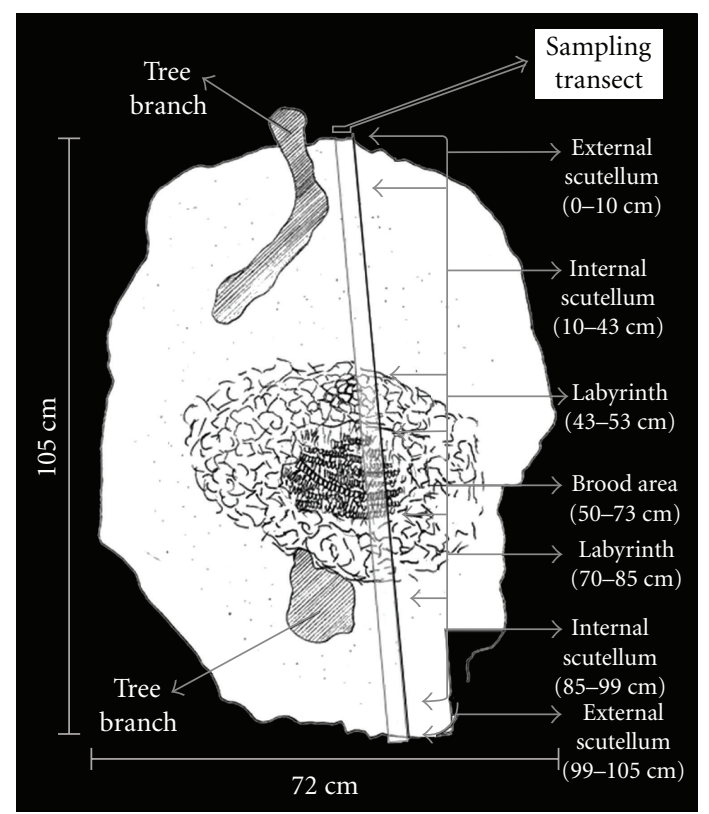

Figure 2: Diagram of scutellum and entire nest of Trigona corvina and the sampling transect.

of material was removed at 30 points, every $5 \mathrm{~cm}$ (Figure 2). Eleven of the samples, spread evenly along the transect, were chemically treated using standard laboratory pollen "acetolysis" protocols with concentrated acids to destroy organic debris, clear, and slightly stain pollen grains [8]. Two tablets of the fern marker spore Lycopodium were added to each sample as a reference standard [9]. This technique allows pollen grain counts to be compared on a volumetric basis, where each Lycopodium clavatum (batch 938934) tablet provided roughly 11000 spores. The proportion of pollen grains to spores indicated their number per cubic $\mathrm{cm}$. Pollen identifications of the acetolyzed pollen were based on collections and a pollen atlas for central Panama [10]. Photomicrographs were made of each species. A pollen diagram, developed for stratigraphic studies, used Tilia and Tilia.graph [11]. For comparative purposes, a single honey sample from a colony of Africanized Apis mellifera and one of Tetragonisca angustula (Meliponini) were analyzed, using $50 \mathrm{~mL}$ of honey (see [12]) taken from the pooled honey contents of the nest, at a Cuurundu site near the former Dressler residence, in 2002.

\section{Results}

The scutellum (the enclosure made by the bees and surrounding their nest) was thick and hard, covering the entire nest, particularly the upper portion (Figure 2). Seventy-two species and 65 genera in 41 plant families were identified in the total nest scutellum transect (Figures 3 and 4). Samples of the 15 most voluminous pollen species in the diet of Trigona corvina are depicted in Figure 3. The five palm species were not only best represented as a single family but had high total pollen percentages within the cubic $\mathrm{cm}$ samplesfrom $30 \%$ to $50 \%$. Roystonia (an introduced species) was dominant, and Cocos nucifera, also an introduced species, was present in relatively large amounts. The nectarless secondary growth tree Cecropia peltata attained counts of $23 \%$ to $47 \%$ of total grains in individual samples from the transect. Most remaining species of 39 families were insignificant to sporadic (Figure 4), but more noteworthy were Bombacaceae (now called Malvaceae, 4 species), Burseraceae (1 species), Euphorbiaceae (4 species), and Anacardiaceae, all of which are trees. The dominant herb pollen was Mimosa pudica, a nectarless scandent shrub. Lianas had low representation, including Machaerium (Papilionoideae) and the nectarless Davilla (Dilleniaceae). Tetragonisca angustula (Figure 5) among the commonest nesting meliponines in the area did not use resources closely similar to either Apis or T. corvina. 


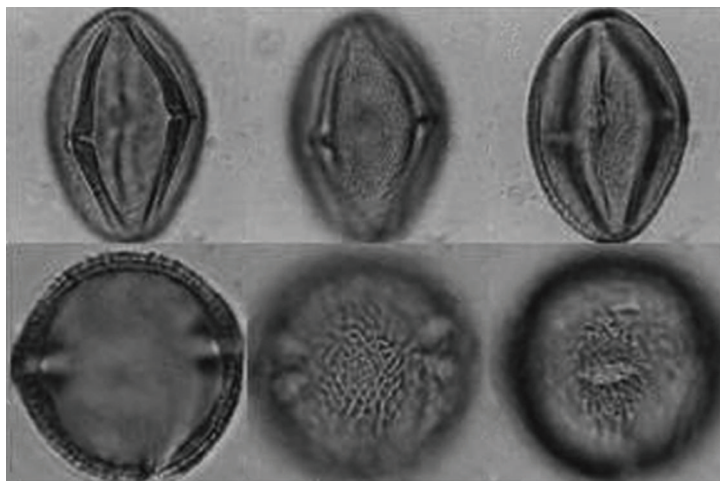

1

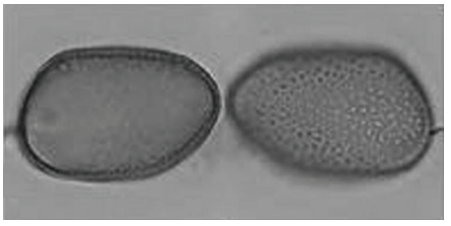

4
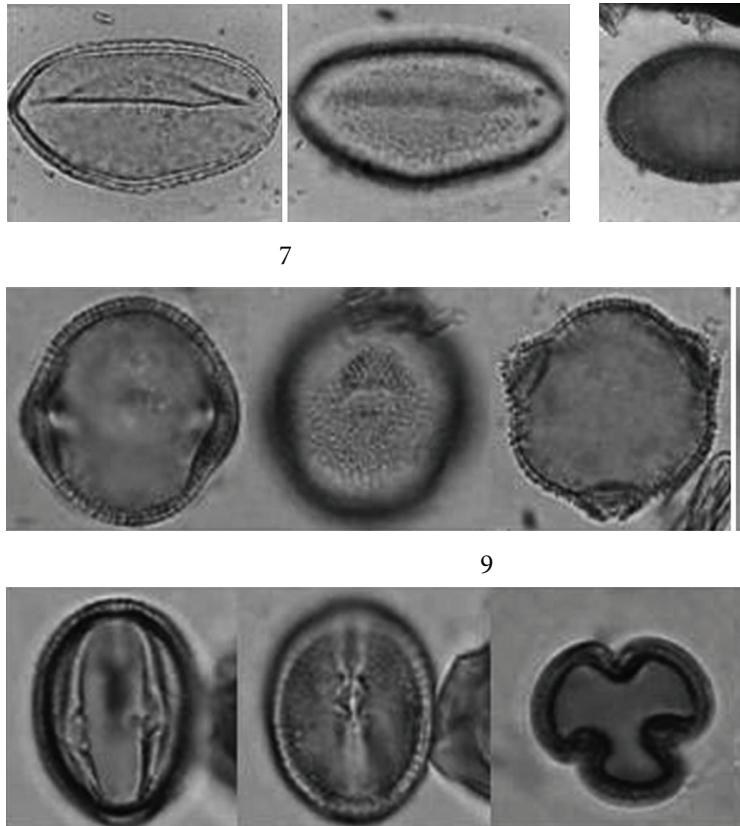

11

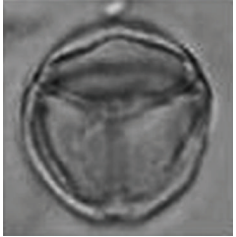

13

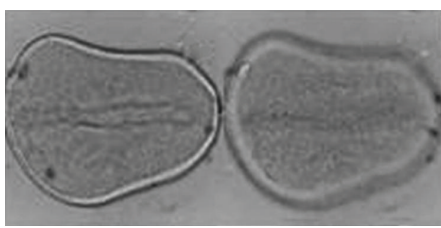

5

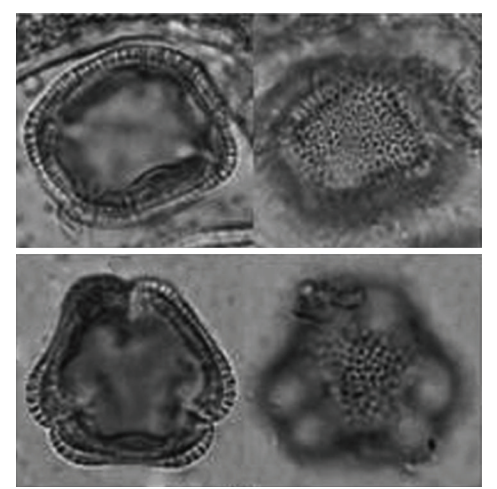

2

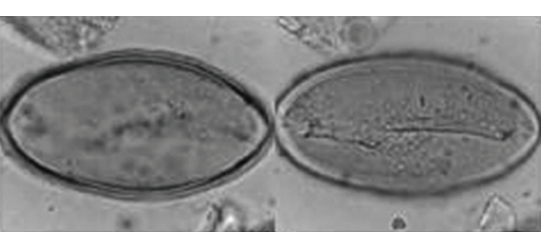

6

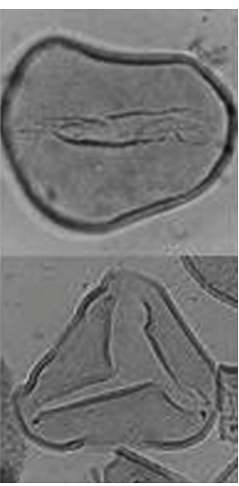

3

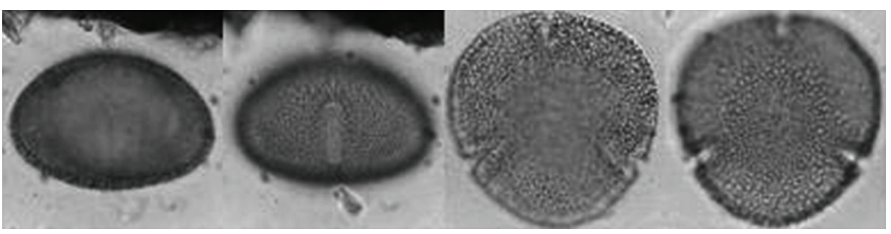

8

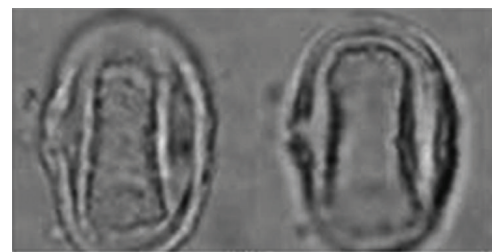

10

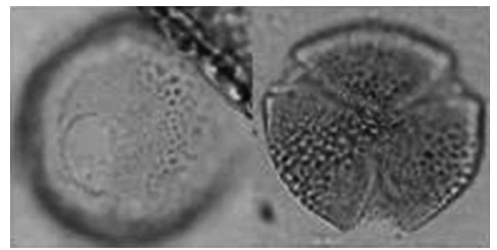

12

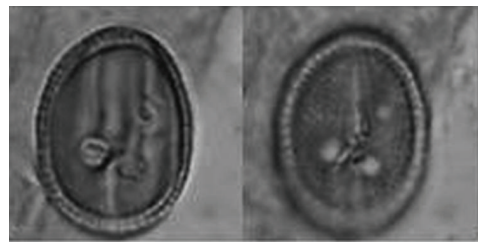

15

FIGURE 3: Representative common pollen species taken from nest scutellum. Anacardiaceae: Spondias mombin (1); Araliaceae: Didymopanax morototoni (2); Arecaceae: Cocos nucifera (3); Crysophilla warcewiczii (4); Elaeis oleifera (5); Phytelephas (6); Attalea butyracea (7); Bombacaceae: Pseudobombax septenatum (8); Burseraceae: Bursera simarouba (9); Cecropiaceae: Cecropia peltata (10); Euphorbiaceae: Chamaesyce (11); Dilleniaceae: Davilla nitida (12); Mimosoideae: Mimosa pudica (13); Papilionoideae: Erythrina fusca (14); Machaerium (15). Images not to scale, photographs $\times 1000$. 


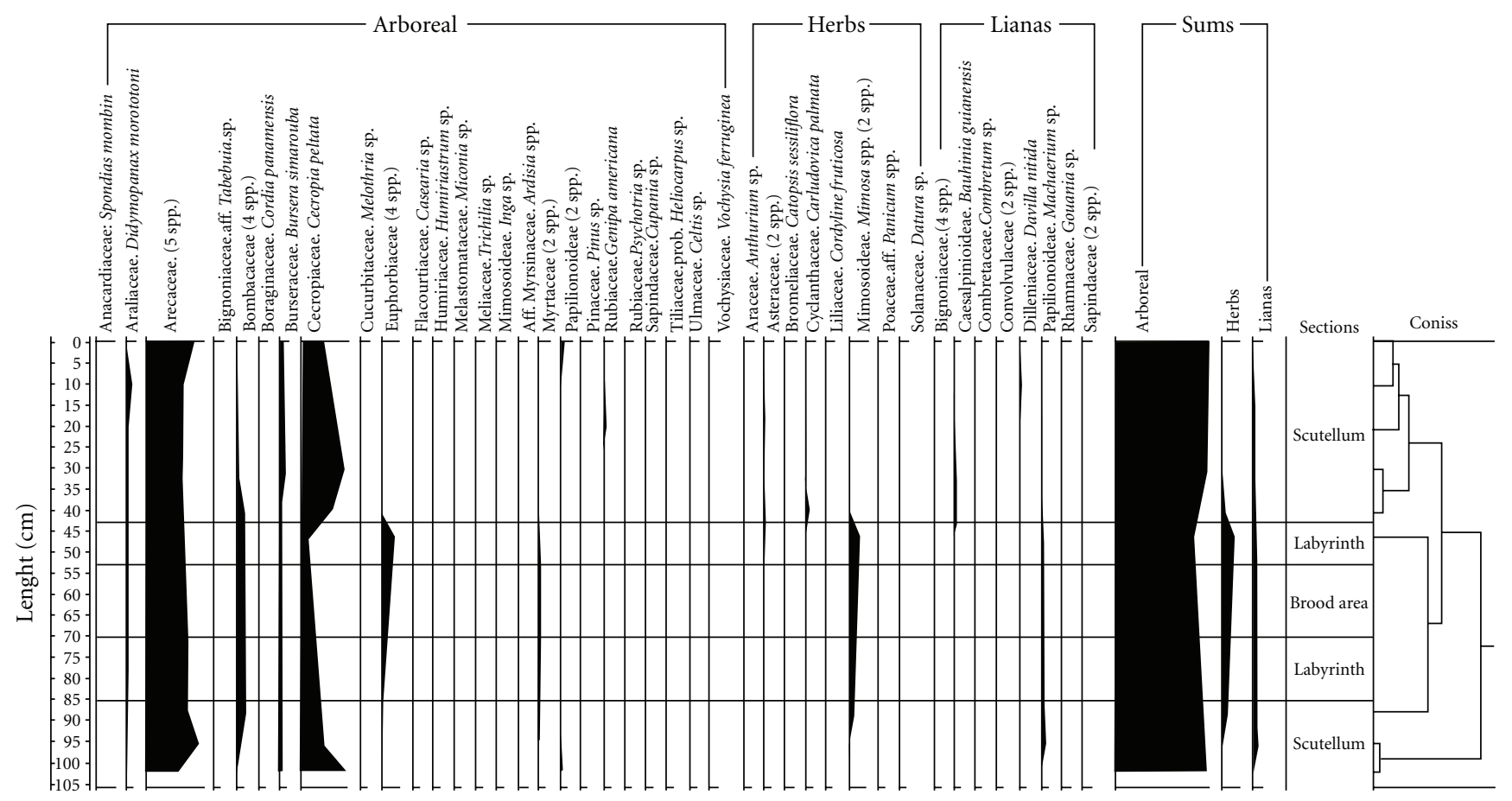

FIGURE 4: Scutellum pollen stratigraph of the 20-year-old nest of Trigona corvina.

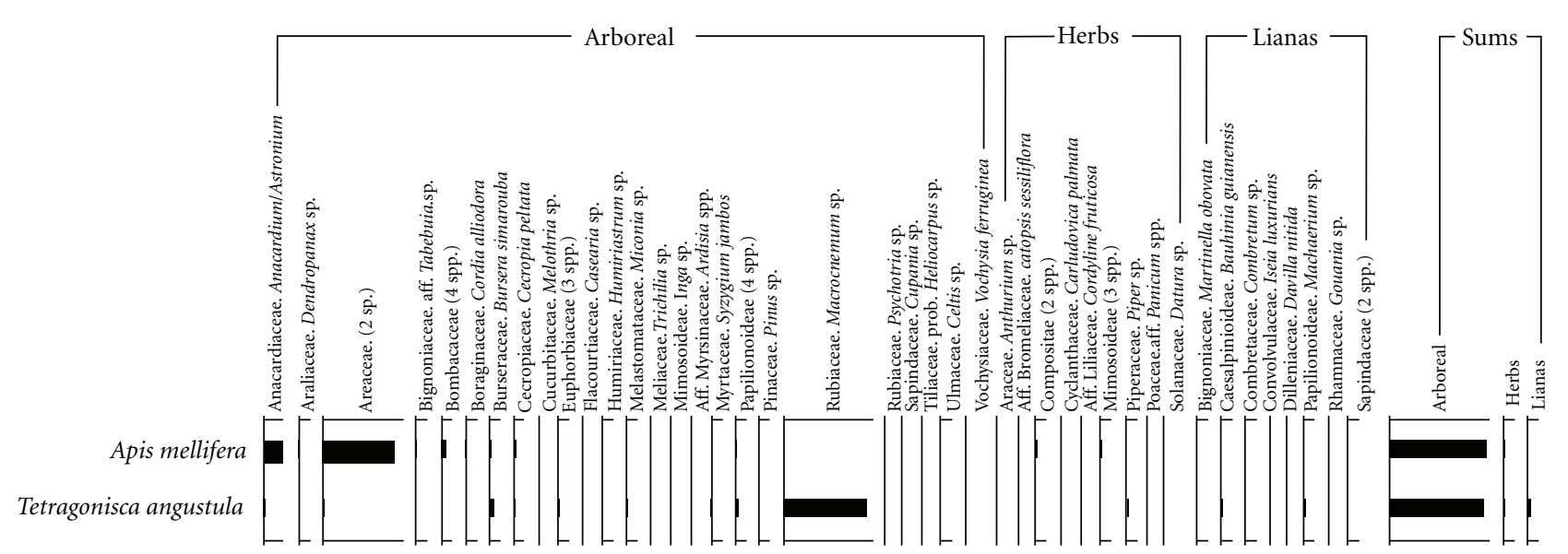

FIGURE 5: Pollen graph for a honey sample analyzed from the study area in mid 2002, from a resident colony of Africanized honey bees and from an abundant native stingless bee, Tetragonisca angustula.

The pollen stratigraphic diagram given in Figure 4 indicates a process of pollen deposition by bees in the nest scutellum, and the volumentric contribution of each species and family, over time. The larger extent of scutellum above the brood area is seen in Figure 2. On the far right of the graph, the "CONISS" is a cluster analysis of similarity in nest composition among transect samples. The composition pattern of pollen deposition by the brood area and labyrinth (the nonbrood or food area within the scutellar covering of the nest) were generally similar, as were the samples taken within the upper or lower scutellum. These form the three main branches of the dendrogram. The upper scutellum and mid nest were of similar composition, while the lower scutellum was the outlier-least similar in grain species and abundance.

The pollen grain concentration per cubic $\mathrm{cm}$ was extraordinary, from 27 to 49 million. If an egg-shaped nest structure is modeled on this basis [13], then the nest, an egg-shaped object measuring $105 \times 72 \mathrm{~cm}$ maximum diameter, was made from the pollen or exines of $2.5 \times 10^{13}$ 
(25 trillion) grains. This estimate does not subtract volume of the labyrinth, involucrum, brood and stored honey, and pollen, in the center of the nest.

\section{Discussion}

Nest Biology. The pollen study yielded a wealth of data not only on bee biology but also on vegetation dynamics. Early studies of nest architecture in Neotropical Trigona mentioned an earthen, clay, or cerumen and resin scutellum, incorporating vegetation and also vertebrate feces. These were found not to be major scutellum components. The scutellum is reminiscent of decaying wood. Nogueira-Neto [4] first clarified that the scutellum of T. spinipes, under microscopic examination, consisted primarily of the normal debris collected within the nest-fecal meconia and pupal exuviae, plus some mites, cerumen, resin (sometimes called geopropolis), and disarticulated bees. He did not mention pollen, but the meconium is pollen voided in the cell before the cocoon is spun by a mature larva. It is a thin layer on the base of the cocoon. Further work with garbage pellets ejected outside the nest of an Asian stingless bee [14] verified that bases of used brood cells and pollen exines were the major garbage components. The accumulated solid debris in the nest cavity of four nests of Cephalotrigona zexmeniae was analyzed and found to consist of identifiable pollen, and little else [2].

After foundation of the nest and its initial growth, the brood area of $T$. corvina was encased in an increasingly thick layer of excreted pollen taken from the emerged brood cells and ostensibly deposited first in refuse piles within the nest, as noted for stingless bees in general $[1,15]$. We speculate that workers did not eject pollen feces or garbage pellets in the normal way but incorporated them into the external nest area, outside the involucrum, and gradually formed the thick scutellum. Young adult bees may also contribute directly to this deposit, by defecating on the scutellum after pollen-rich initial adult meals (see also [4]). The farthest outer regions of the nest are sheathed in thin concentric sheaths of hardened and brittle resin or cerumen, which crumble when touched, and allow defending bees to exit en mass [1]. Immediately inside the outermost sheaths and their supporting pillars, the internal scutellum was $43 \mathrm{~cm}$ thick above and $35 \mathrm{~cm}$ below. It is likely that no material initially filled such passageways. This area was gradually packed with the pollen feces, which solidified in the layers between what may have been sheaths of cerumen and resin, or the loosely arranged small connectives which formed a labyrinth (neither involucrum or food storage structures).

A young nest is approximately half the size of the old nest we examined [5] but the total brood area may undergo little change in the life of the colony. This may be the result of initial scutellum building. The middle $42 \mathrm{~cm}$ of the nest at the time it fell to the ground was occupied by the brood combs, pollen and honey storage pots, and a labyrinth of involucral sheaths and pillars that enclosed the area (Figure 2). Perhaps part of this area was the first to be protected by the pollen exine scutellum, and later, the used brood cell bases with pollen feces and little or no other material were transferred toward the exterior of the nest. The brood area could thus not expand. The pollen taxonomic composition similarities indicated by the CONISS analysis and dendrogram (Figure 4), and similarities in the width of pollen deposition of Cecropia at the $95-100 \mathrm{~cm}$ area and the 0-40 level, suggest that pollen feces first filled space around the brood and on the top of the nest and later were deposited below the brood area. The properties of pollen exines, like an insect cuticle, are near indestructibility from sun, wind, rain, and ultraviolet radiation [16, 17]. Insulation from direct sunlight, commonly reaching $40^{\circ} \mathrm{C}$ at the exposed nest surface (DWR unpublished data, Panama Metropolitan Park, Smithsonian Canopy Crane), augments the nesting value of scutellum. In addition, defense by thousands of flying, aggressive workers protects the entire nest. Potential mechanical protection or support, from above or below, differed by about $10 \mathrm{~cm}$ of scutellum. We suggest that the scutellum provides defense yet little structural support, but insulates and protects the nesting colony. It is also possible that the small, basal scutellum seen in the nests of $T$. dallatorreana and T. nigerrima [3] is a result of young nest age, but it may also show that bees select nesting branches unable to support the weight of a full scutellum.

Only one meliponine genus, the Neotropical Cephalotrigona, does not eject its colony trash and instead accumulates a deposit of up to several kilograms in the base of the nest cavity. This compact bee excreta has been used to characterize the entire pollen spectrum of colony resources [2]. Trigona corvina, T. spinipes, and T. amalthea $[4,7,18,19]$ each make a full-size scutellum. Its texture, size, smell, and, in the first two cases, microscopic content indicate pollen exines and bee excreta. Trigona amalthea (syn. T. trinidadensis, nec. T. silvestriana; J. S. Moure, quoted on [18, page 135]) is the largest stingless bee of Mexico and Central America, but few nests have been dissected $[7,19]$. One that was examined by the authors had a complete scutellum that was heavy. Several clades within Trigona [3] may also prove to have pollen records residing in excreta that comprise their nest scutellum. Unlike some indications [3] most of the nest scutellum in T. corvina was built on top of the nest (Figure 2). If bees do not switch colony behavior to perform normal meliponine trash ejection, the mature nest scutellum means that time is running out for the colony. For an exposed nest on a tree branch, or for a gigantic nest such as that of T. amazonensis on a tree trunk $[3,20]$, the weight of the nest may cause it to fall from the substrate. In kind, the accumulation of colony feces at the base of the nesting cavity of Cephalotrigona will eventually prevent colony survival.

Landscape Changes. The data indicate some interesting changes in pollen use by $T$. corvina which coincide with arrival of a major competitor, invasive Africanized honey bees, and with disturbances to the surrounding forest. Our interpretation of stratigraphic results from the bee nest includes landscape changes and colonization, in 1984, of Panama city and later western Panama by large numbers of Africanized honey bee colonies [21, 22]. The melissopalynological sample (honey [12]) from a nest of Africanized Apis mellifera also at Curundu Flats, and one of another resident 
stingless bee, Tetragonisca angustula, less than $100 \mathrm{~m}$ from the nest site of T. corvina in Figure 5, are discussed below.

In our concept of nest construction, the central portion of the pollen diagram (Figure 4), consisting of transect points from approximately 40 to $85 \mathrm{~cm}$, depicts the forage landscape when the colony was founded. In early 1982 the area surrounding the study nest was cleared of regrowth for nearly $400 \mathrm{~m}$, as overgrown roads were cleared and repaved. This created an edge habitat in which Cecropia, a pioneer secondary growth tree, expanded along the newly opened areas (see $[23,24]$ ). This pollen, among the dominant pollens used by $T$. corvina, was several times more abundant in the outer nest layers, particularly toward the top of the nest.

Honey Bee Impact and Stingless Bee Foraging Behavior. A second conspicuous change in the pollen profile is virtual disappearance of Euphorbiaceae, Bombacaceae (now Malvaceae), and Mimosoideae during a later time in the colony's existence. After the nest was four years old, colonization of central Panama by Africanized honey bees occurred [21], which use not only the three plant families mentioned above but also palms and Cecropia [24-26] (Figure 5). Recently, this invasive bee also was found using the scutellum of $T$. corvina to house a colony (Figure 1). In the colony pollen profile, Trigona corvina may have lost significant resources (see [27]) to the Africanized honey bees, while continuing to use pollen of palms, Burseraceae, and Cecropia (Figures 4 and 5). It is not known whether intensive competition led to the demise of the colony depicted in Figure 1(b), but it has been inferred that Africanized honey bees often concentrate on resources in more open habitats [28] and this is where nests of T. corvina also occur (pers. obs., $[5,29]$ ).

The single honey samples of $A$. mellifera were collected in May of 2002 but had some of the same principal species noted for $T$. corvina. These are obviously not all nectar sources. All topical honey carries "contaminant" pollen from nectarless plants, such as Cecropia, Mimosa pudica, grasses, and Davilla. No quantitative comparison can be given of different plant species from pollen counts in honey, and thus no quantitative comparison can be made. For quantitative appraisal of which pollen sources are most important to Africanized honey bees, see [24, 25]. In the present discussion, relative importance of a plant species to Apis is not so relevant as the relative importance to its competitor (see [27]). Apis mellifera has a very large diet breadth but does specialize on highly rewarding flower patches, such as flowering trees $[20,25]$.

The "powerhouse" colonies of Apis and Trigona selected the richest local resources, but the unaggressively foraging T. angustula did not, as elucidated below. The degrees to which these species chose resources by species (rather than by their relative abundance), by competitor presence, or by density in the habitat are factors that must be considered in assessing whether any bee is "selective." For the moment, the best hypothesis seems to be that persistent, large, and dense inflorescences of common species, and therefore the best potential resources, were monopolized by Apis and Trigona. Palm inflorescences present a dense, highly rewarding pollen resource used extensively both by honey bees and highly aggressively group-foraging stingless bees. This pollen barely appeared in the honey of Tetragonisca angustula (Figure 5). The Trigona corvina is foraged by recruiting hovering groups of a few hundred foragers to tree canopies which are dominated by a few individual colonies [30]. The nests of aggressively foraging Trigona are not randomly distributed in the landscape but are regularly spaced [31] to avoid precipitous battles that occur between colonies attempting to dominate a rich, concentrated resource $[20,32]$. Cecropia peltata also has clusters of catkin-like inflorescences with abundant pollen, often dispersed by wind.

The diet of Trigona corvina included Cavanillesia (Bombacaceae), and the source trees grow within Parque Metropolitano, at least $1 \mathrm{~km}$ from the nest. This observation allows an estimate of minimum forager activity range, and indicates colony exploitation of over $3.14 \mathrm{~km}^{2}$. However, bees of similar size, Trigona fulviventris, forage at least $2 \mathrm{~km}$ from their nest, documented in a single instance on Barro Colorado Island, Panama, where a Piper inflorescence near the laboratory clearing received a visit from a bee marked at its nest on Zetek trail. Conservatively, the local flora within access to the colony of T. corvina contained some 500 species of flowering plants including 100 or more tree species [33], the main resources of Trigona corvina. Among these, Trigona corvina added exotic or disturbed forest-edge species to their principal plant resources. They used relatively few plants and growth forms, rarely using lianas or shrubs (Figure 4) [2].

Thus, similar to the "trace fossils" provided in coprolites (fossilized excrement) the scutellum in a nest of T. corvina provides a summary of the colony history and ecological factors that affect historical data. Rigorous analysis of pollen accumulations provides a new avenue for exploring and applying the information residing in stingless bee nests.

\section{References}

[1] D. W. Roubik, "Stingless bee nesting biology," Apidologie, vol. 37, no. 2, pp. 124-143, 2006.

[2] D. W. Roubik and J. E. Moreno, "Generalization and specialization by stingless bees," in Proceedings of the 6th International Bee Research Conference on Tropical Bees (IBRA '00), pp. 112118, Cardiff, UK, 2000.

[3] C. Rasmussen and J. M. F. Camargo, "A molecular phylogeny and the evolution of nest architecture and behavior in Trigona s.s. (Hymenoptera: Apidae: Meliponini)," Apidologie, vol. 39, pp. 102-118, 2008.

[4] P. Nogueira-Neto, "The scutellum nest structure of Trigona (Trigona) spinipes Fab. (Hymenoptera: Apidae)," Journal of the New York Entomological Society, vol. 70, pp. 239-264, 1962.

[5] C. D. Michener, "Notes on the habits of some Panamanian stingless bees," Journal of the New York Entomological Society, vol. 54, pp. 179-197, 1946.

[6] A. Müller and M. Kuhlmann, "Pollen hosts of western palaearctic bees of the genus Colletes (Hymenoptera: Colletidae): the Asteraceae paradox," Biological Journal of the Linnean Society, vol. 95, pp. 719-733, 2008.

[7] A. Wille and C. D. Michener, "The nest architecture of stingless bees with special reference to those of Costa Rica (Hymenoptera: Apidae)," Revista de Biología Tropical, vol. 21, supplement 1, pp. 8-278, 1973. 
[8] G. Erdtman, Handbook of Palynology. An Introduction to the Study of Pollen and Spores, Munksgaard, Copenhagen, Denmark, 1969.

[9] J. Stockmarr, "Tablets with spores used in absolute pollen analysis," Pollen et Spores, vol. 13, pp. 615-621, 1971.

[10] D. W. Roubik and J. E. Moreno, Pollen and Spores of Barro Colorado Island, Monographs in Systematic Botany, vol. 36, Missouri Botanical Garden, St. Louis, Mo, USA, 1991.

[11] E. Grimm, "Tilia and Tilia-graph: pollen spreadsheet and graphic programs," in Proceedings of the 8th International Palynological Congress (IPC '92), vol. 56, Aix-en-Provence, France, September 1992.

[12] J. Louveaux, A. Maurizio, and G. Vorwohl, "Methods and terminology in melissopalynology," Review of Palaeobotany and Palynology, vol. 59, pp. 139-157, 1978.

[13] D. W. Roubik, "Nest and colony characteristics of stingless bees from French Guiana," Journal of the Kansas Entomological Society, vol. 52, pp. 443-470, 1979.

[14] T. Eltz, C. A. Brühl, S. van der Kaars, and K. E. Linsenmair, "Assessing stingless bee pollen diet by analysis of garbage pellets: a new method," Apidologie, vol. 32, pp. 341-353, 2001.

[15] P. Nogueira Neto, Vida e Criação de Abelhas Indígenas Sem Ferrão, Editora Tecnapis, Sao Paulo, Brazil, 1997.

[16] R. G. Stanely and H. F. Linskens, Pollen: Biology, Biochemistry and Management, Springer, New York, NY, USA, 1974.

[17] A. G. Richards, "The chemistry of insect cuticle," in Biochemistry of Insects, M. Rockstein, Ed., pp. 205-232, Academic Press, New York, NY, USA, 1978.

[18] M. C. Almeida, "Duas especies novas de Trigona (s. str.) (Apidae, Meliponinae) da região neotropical," Dusenia, vol. 14, pp. 129-144, 1984.

[19] D. W. Roubik, "Nest and colony characteristics of stingless bees from Panama," Journal of the Kansas Entomological Society, vol. 56, pp. 327-355, 1983.

[20] D. W. Roubik, Ecology and Natural History of Tropical Bees, Cambridge University Press, New York, NY, USA, 1989.

[21] M. M. Boreham and D. W. Roubik, "Population change and control of Africanized honey bees in the Panama Canal area," Bulletin of the Entomological Society of America, vol. 33, pp. 3439, 1987.

[22] D. W. Roubik, "African honey bees augment neotropical coffee yield," in Pollinating Bees: The Conservation Link Between Agriculture and Nature, P. G. Kevan and V. L. ImperatrizFonseca, Eds., pp. 255-266, Ministry of Environment, Brasilia, Brazil, 2002.

[23] D. F. Whigham, I. Olmsted, E. C. Cano, and M. E. Harmon, "The impact of Hurricane Gilbert on trees, litterfall, and woody debris in a dry tropical forest in the northeastern Yucatan Peninsula," Biotropica, vol. 23, pp. 434-441, 1991.

[24] R. Villanueva-G. and D. W. Roubik, "Why are African honey bees and not European bees invasive? Pollen diet diversity in community experiments," Apidologie, vol. 35, pp. 550-560, 2004.

[25] D. W. Roubik, "An overview of Africanized honey bee populations: reproduction, diet and competition," in Proceedings of the International Conference on Africanized Honey Bees and Bee Mites, G. Needham, R. Page, and M. Delfinado-Baker, Eds., pp. 45-54, Horwood, Chichester, UK, 1988.

[26] D. W. Roubik and M. M. Boreham, "Learning to live with Africanized honeybees," Interciencia, vol. 15, pp. 146-153, 1990.
[27] D. W. Roubik and R. Villanueva-G, "Invasive Africanized honey bee impact on native solitary bees: a pollen resource and trap nest analysis," Biological Journal of the Linnean Society, vol. 98, pp. 152-160, 2009.

[28] B. J. Brosi, G. C. Daily, T. M. Shih, F. Oviedo, and G. Durán, "The effects of forest fragmentation on bee communities in tropical countryside," Journal of Applied Ecology, vol. 45, pp. 773-783, 2008.

[29] M. D. Breed, T. P. McGlynn, M. D. Sanctuary, E. M. Stocker, and R. Cruz, "Distribution and abundance of colonies of selected meliponine species in a Costa Rican tropical wet forest," Journal of Tropical Ecology, vol. 15, pp. 765-777, 1999.

[30] D. W. Roubik, "Tropical bee colonies, pollen dispersal and reproductive gene flow in forest trees," in Modelling and Experimental Research on Genetic Processes in Tropical and Temperate Forests, B. Degen, M. D. Loveless, and A. Kremer, Eds., pp. 31-41, Embrapa Amazônica Oriental, Belém, Pará, Brazil, 2002.

[31] S. P. Hubbell and L. K. Johnson, "Competition and nest spacing in a tropical stingless bee community," Ecology, vol. 58, pp. 949-963, 1977.

[32] L. K. Johnson and S. P. Hubbell, "Aggression and competition among stingless bees," Ecology, vol. 55, pp. 120-127, 1974.

[33] M. D. Correa, C. Galdames, and M. S. de Stapf, Catálogo de las Plantas Vasculares de Panamá, Quebecor World Bogota, Bogota, Colombia, 2004. 

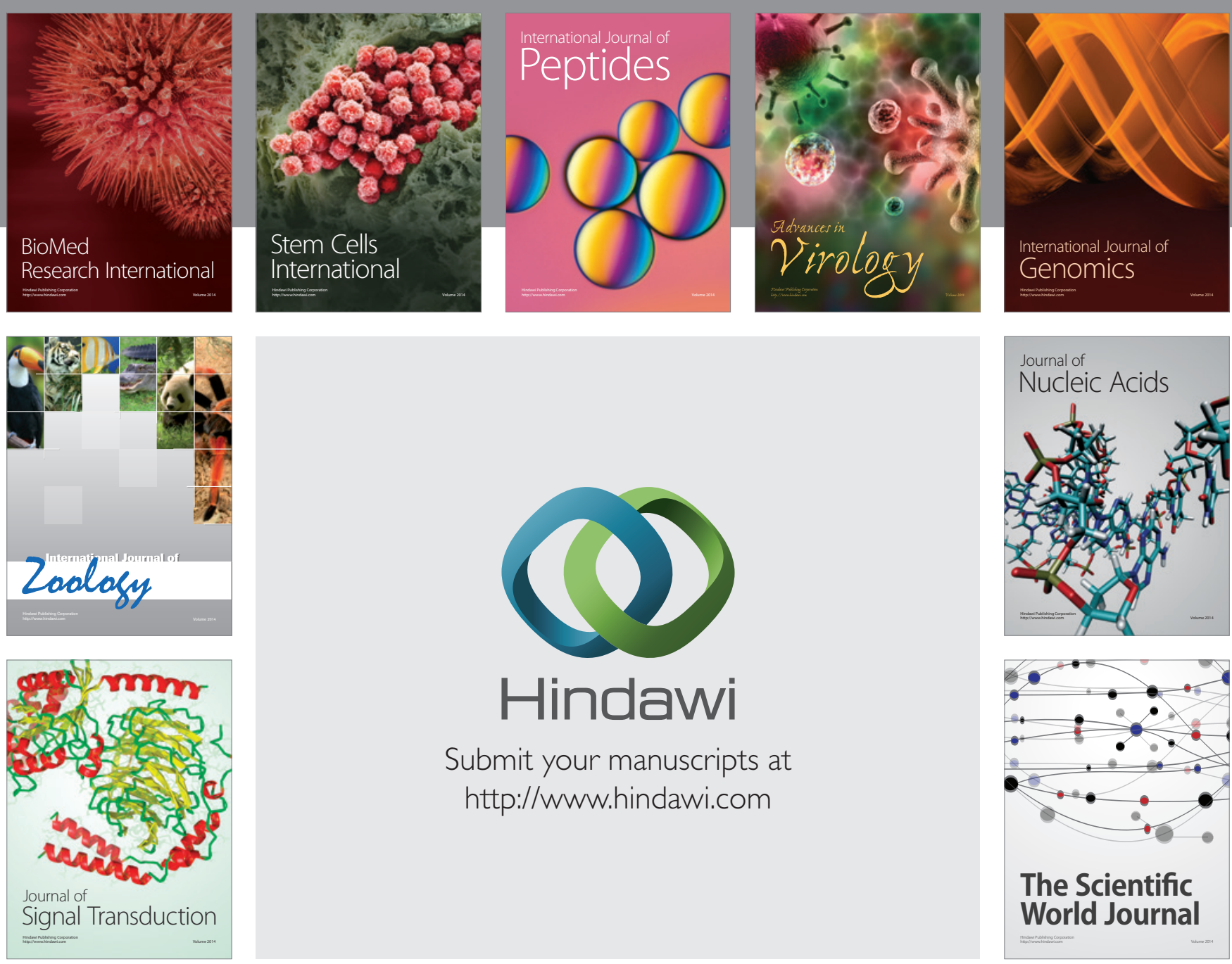

Submit your manuscripts at

http://www.hindawi.com
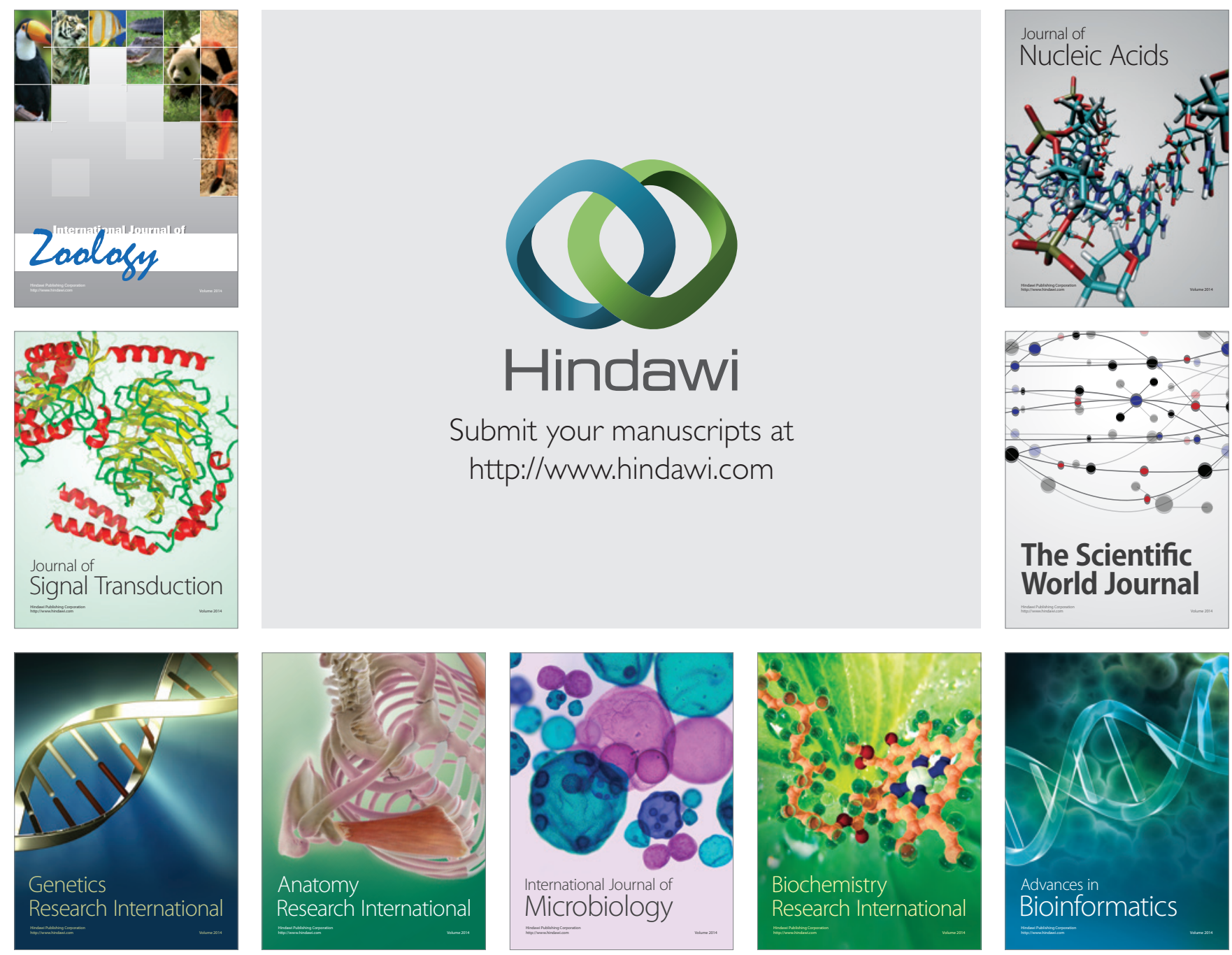

The Scientific World Journal
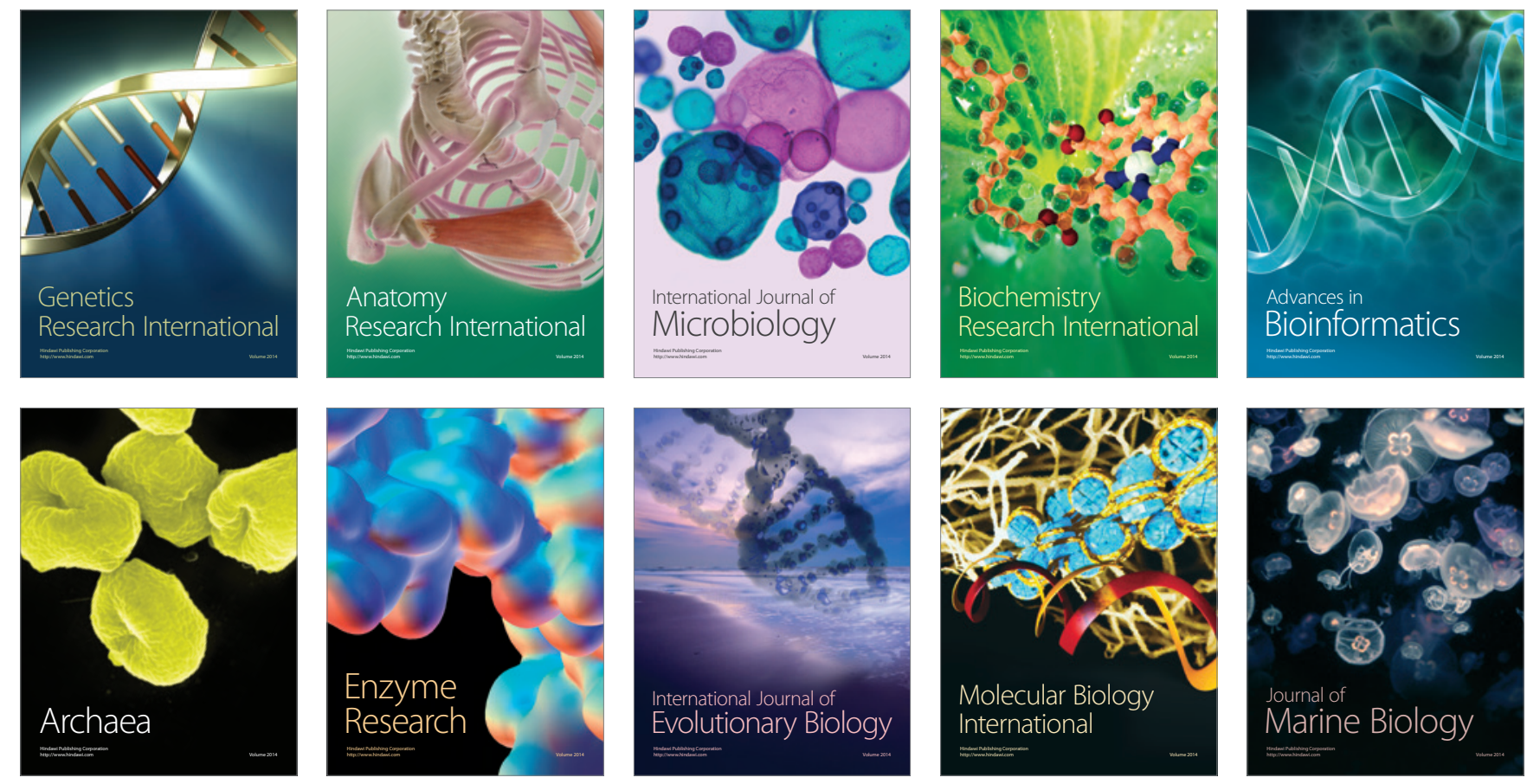